\title{
O desafio de educar na era digital: educações $^{1}$
}

\author{
Nelson de Luca Pretto \\ Universidade Federal da Bahia, Brasil
}

\begin{abstract}
Resumo
O artigo apresenta uma visão panorâmica do desenvolvimento científico e tecnológico da comunicação e das diversas linguagens (co-)existentes que se articulam intensamente a partir da enorme presença das tecnologias digitais. Analisa-se a implantação das redes digitais e dos processos colaborativos de produção de conhecimento e as políticas públicas brasileiras para o campo da cultura digital, destacando-se o uso das redes de compartilhamento, com ênfase no software livre e na produção coletiva. A partir desses pressupostos, discute-se a importância da relação da educação com a cultura. Desenvolvese a idéia de uso intenso das redes colaborativas nos processos educacionais, com a montagem de comunidades horizontais de produção de culturas e conhecimentos. Ao final, reflete-se mais detalhadamente sobre a proposta de pensar a educação numa perspectiva plural, ou seja, em educações.
\end{abstract}

Palavras-chave

Educação; Cultura digital; Comunicação digital; Redes

Conhecemos não para sermos donos. Mas para sermos mais companheiros das criaturas vivas e não vivas com quem partilhamos esse universo. Para escutarmos histórias que nos são, em todo momento, contadas por essas criaturas.

Mia Couto, 2005 
Anarquia científica, todas as vozes marginalizadas deveriam participar.

Paul Feyerabend, 1996

\section{Introdução}

Os desafios não são pequenos. O mundo contemporâneo tem trazido surpresas e situações de tal complexidade que nos têm deixado perplexos, quase atordoados. Não temos mais possibilidade de analisar nenhuma área com abordagens simplificadas, meramente isolando-se variáveis, com o objetivo de se buscar elementos definidores de uma ou outra, separadamente. Mais do que nunca, hoje, pensar sobre a educação é, simultaneamente, pensar na ciência, na tecnologia, na saúde e, principalmente, na cultura e, tudo isso, de maneira articulada.

Neste texto, nos propomos a, inicialmente, desenhar uma visão panorâmica do desenvolvimento científico e tecnológico, do sistema de comunicação planetário e das diversas linguagens (co)existentes que se articulam de forma intensa a partir da enorme presença das tecnologias digitais, mais especificamente as de informação e comunicação. Ao final, buscamos refletir mais detalhadamente sobre aquilo que nos parece ser 0 grande desafio para a educação: continuaremos a pensá-la numa perspectiva singular ou deveríamos pensá-la em uma perspectiva plural, em educações?

\section{Transformações na produção de conhecimento}

Do ponto de vista científico e tecnológico, constatamos profundas transformações na maneira como produzimos conhecimento contemporaneamente. Vivemos em um mundo onde as grandes velocidades e, principalmente, a aceleração com que os aparatos se deslocam, provocam modificações profundas nas nossas formas de pensar e de ser. Movemo-nos em velocidades nunca dantes experimentadas. A humanidade passou de deslocamentos que giravam em torno dos três a $10 \mathrm{~km} / \mathrm{h}$ - velocidade do caminhar ou dos animais - para velocidades em torno de $1.000 \mathrm{~km} / \mathrm{h}$ - a dos aviões supersônicos. Tudo isso no tempo equivalente à vida de apenas uma ou duas gerações. Para o pesquisador argentino Alejandro Piscitelli (2002), essas mudanças provocaram um profundo deslocamento existencial do ser humano, com consequências diretas na relação sujeito/objeto, já que 
componentes tecnológicos passam a ser elementos fundantes de uma nova estruturação cultural, transformando a relação homem-máquina, sobretudo em função do desenvolvimento da nanotecnologia. Exemplo mais marcante dessa relação é o trabalho do artista multimídia brasileiro Eduardo $\mathrm{Kac}^{2}$, com sua arte transgênica. Tais mudanças estão diretamente associadas às radicais transformações na forma como produzimos conhecimentos, uma vez que, segundo o físico italiano Marcelo Cini em seu livro O paraíso perdido, "[...] passamos de um mundo onde as leis científicas estavam centradas na ordem - um modelo baseado em leis simples que davam conta de sua explicação - para um sistema mais complexo, onde a desordem, a irregularidade, o inesperado, estão presentes de forma mais intensa" (Cini, 1998, p. 111). As descobertas dos fenômenos caóticos, das relações nãolineares e dos fractais em muito contribuíram para as transformações na maneira como pensamos contemporaneamente, demandando uma ampliação da nossa relação entre tecnologia e cultura, como propõe Mark Poster, ao refletir sobre o virtual. Essa imbricação das tecnologias com a cultura passa a se dar de forma intensa, demandando uma compreensão dessas transformações. Transformação das máquinas mecânicas em máquinas inteligentes, com a inteligência artificial, com os sistemas autoregulados e tudo isso repleto de imagens, sons e textos digitalizados. Nesse sentido, traduzindo a concepção de Poster (2001, p. 146), dizemos: a "[...] disseminação desses sistemas de software-hardware através do espaço social e a instalação de interfaces que unem humanos e máquinas, [cria um] novo agenciamento de configuração", que implica um repensar sobre as nossas relações com as tecnologias.

Todas essas transformações trouxeram para o cenário atual a ideia da chamada sociedade da informação, do conhecimento ou, como prefere Manuel Castells (1996), informacionalismo, no qual um dos elementos marcantes é a velocidade com que as próprias tecnologias, particularmente as de informação e comunicação, se implantam. Há cerca de 60 anos nascia a televisão e, daqui a poucos anos, certamente, não mais a teremos com o atual modelo (Gilder, 1994), que se manteve aproximadamente o mesmo desde o seu nascimento. Para se ter um pequeno exemplo, nos Estados Unidos, o rádio levou 38 anos para ser usado por 50 milhões de pessoas, enquanto que a internet apenas quatro anos (Takahashi, 2000, p. 3). Isso nos mostra que 
uma única geração é capaz de ver nascer e desaparecer uma dessas tecnologias, especialmente as digitais de informação e comunicação, muitas vezes sem nem mesmo se aperceber disso. Implanta-se a cultura da velocidade e essa associa-se, de forma intensa, com a velocidade com que são descartadas soluções tecnológicas que mal foram criadas.

Jeff Bezos, criador da livraria on-line Amazon.com, hoje um império que congrega diversos outros setores e fornecedores, declarou, em 2000, que o senso de urgência se transformou no capital mais importante do momento, justamente porque "quando algo está crescendo $2.300 \%$ ao ano como foi a Net no tempo de criação da Amazon.com, você tem que se mover rápido" (apud Himanen, Torvalds \& Castells, 2002, p. 22). Também muito veloz o desenvolvimento das chamadas tecnologias móveis, sendo exemplo singular os aparelhos celulares, com o seu intenso uso modificando de forma radical as formas de comunicação - e de escrita, como veremos adiante - uma vez que, em função da sua limitação de espaço, novos códigos estão sendo criados e estão circulando em grande velocidade. Os dados sobre esse crescimento são espantosos. Em 1991, existiam no mundo 34 linhas de telefone fixo para cada móvel e, em 2004, as assinaturas de telefones móveis superavam os fixos ("1.748 milhões de celulares/1.198 milhões de telefones fixos") (Leadbeater, 2009, p. 185). Alguns números permitem-nos acompanhar melhor esse crescimento. Nas Filipinas, por exemplo, que possui cerca de 30 milhões de usuários de celulares, estima-se que sejam enviados, em média, 200 milhões de mensagens por dia. Na África, espalha-se o uso de celulares para o pagamento de contas e transferências de dinheiro. Um sistema, chamado Safaricom, lançado em 2008 pela empresa Vodafone, no Kenya, já possuía mais de dois milhões de usuários, com um crescimento de mais de 200 mil por mês (Wrey, 2008). Em outras situações, como por exemplo no dia em que a neve quase parou a Inglaterra em fevereiro de 2009, constatou-se um estupendo crescimento de tráfego na rede, por conta do envio de imagens e comunicados de ausência ao trabalho, com um crescimento de $58 \%$ na operadora Vodafone nos primeiros 30 minutos do dia; a 3Mobile duplicou o envio de imagens para blogs ou sites como o Facebook; e a operadora TMobile registrou um crescimento de $73 \%$, comparado com uma típica segunda-feira (Wrey, 2008). 
No entanto, essas transformações do uso das tecnologias digitais convivem com a chamada mídia tradicional, instituída ainda de maneira oligopolista. $\mathrm{O}$ que se observa nesse campo é a existência de um movimento de concentração da propriedade dos meios de comunicação, com uma enorme concentração de capital em torno de poucas famílias, ou grupos que dominam todo o processo de produção e distribuição simbólica planetária. No Brasil, são apenas seis famílias que comandam esse segmento econômico e mais ou menos o mesmo acontece em termos internacionais. São os proprietários dos meios de comunicação no sentido estrito do termo que, nos últimos anos, ampliam os seus tentáculos para as telecomunicações, bancos, editoras, parques temáticos, provedores de internet, entre outros (Pretto, 2006). Recentemente, acompanhamos mais um desses movimentos, dessa vez com a fusão das empresas Thomson e Reuters, criando o "maior grupo mundial de notícias e informação financeira", segundo o jornal português Público, de 13 de maio de 2007. Nesse particular, e aqui não vou me deter muito no tema, as discussões sobre o sistema brasileiro de TV digital precisam ser vistas numa outra perspectiva que não a da pura e simples emissão de informações, tendo agora apenas uma melhor qualidade de som e imagem ${ }^{3}$. Aqui, a apropriação das tecnologias digitais pode ser importante elemento no sentido de uma ampliação do acesso por boa parte da população que ainda está excluída da chamada cibercultura. Caso contrário, não será possível trabalhar com uma outra perspectiva, horizontal, que possibilite a quebra da lógica vertical dos atuais sistemas de comunicação (mainstream media), onde poucos grupos produzem e uma imensa maioria consome, agora em alta definição. A partir da implantação de um sistema com interatividade plena, vislumbra-se a criação - potencialmente, é bom que se ressalte novamente isso - de redes de conexões que viabilizariam outras possibilidades para a educação e para a cidadania. Mas, insisto, essas são apenas potencialidades, porque se $o$ acesso não for democratizado e se as formas de produção não forem descentralizadas, não se enfrentará nenhum dos desafios que temos pela frente e que não são poucos, como estamos a ver.

Assim, a compreensão do significado das redes que se instalam a partir dos aparatos técnicos digitais contemporâneos demanda que se empreste sentido à própria natureza da rede. Dessa forma, pensamos que, 
intensificando a implantação dessas redes de comunicação horizontal, novas possibilidades emergem, mexendo com os tradicionais vetores de desenvolvimento que sempre atuaram a partir dos grandes centros, espalhando-se para a periferia, da mesma forma que das capitais para o interior do país, como se esses fossem espaços de menor valor, espaços virgens que, se conectados através das redes, iriam ser resgatados de sua pureza e ingenuidade. O estabelecimento de redes horizontais é de fundamental importância para a adoção de outra perspectiva comunicacional, uma vez que, ao conectarmos uma nova região na rede, ambas se transformam, a região e a rede. São esses, portanto, elementos que "interferem" na forma de organização dos territórios e isso existe desde há muito, não sendo algo novo que tenha surgido apenas a partir das redes digitais (Dias, 1995, p.148). No entanto, a temática reaparece agora, afirma Leila Dias, "[...] de outra forma, renovada pelas grandes mudanças deste final de século [século $\mathrm{XX}$ ], renovada pelas descobertas e avanços de outros campos disciplinares". Mais importante para nós e, de acordo com a autora, é que "[...] as redes não vêm arrancar territórios 'virgens' de sua letargia, mas se instalam sobre uma realidade complexa que elas vão certamente transformar, onde elas vão igualmente receber a marca" (Dias, 1995, p. 148).

Essa perspectiva de rede, que nos leva diretamente à ideia do pensar coletivo, traz para o centro deste debate a concepção de produção colaborativa. Exemplo maior no campo científico é o projeto Genoma, iniciado com as primeiras pesquisas que tiveram lugar no Laboratório de Biologia Molecular de Sydney Brenner, em 1965, com rápida expansão, a partir da formação de redes de articulações abertas, num "ciclo virtuoso de partilha de conhecimento" (Leadbeater, 2009, p. 63), única possibilidade para o desenvolvimento de projeto de tão grande monta. Ainda de acordo com Leadbeater (2009, p. 63), o projeto congregava apenas 24 participantes em 1975 , tendo crescido para mais de 1.600 , com uma listagem de cinco mil conexões em torno do projeto em 2002. Outro histórico exemplo de funcionamento em rede é o do projeto de investigação astronômica, desenvolvido desde 1999 pela Universidade da Califórnia, a partir do compartilhamento da capacidade de processamento dos computadores pessoais espalhados pelo mundo afora. Essa rede, formada por voluntários que disponibilizam seus computadores enquanto estes estão ligados mas não 
em uso, articulando uma capacidade de processamento impensável para um único computador, mesmo nos tempos atuais. O Projeto SETI@Home 4 conecta hoje cerca de 4,5 milhões de pessoas ao redor do mundo (Benkler, 2006, pp. 81-83). Um último exemplo, e esse significativo para a abordagem que aqui fazemos, é o do movimento de software livre. Desde 1991, quando pela simples ação de Linus Trovals de disponibilizar na ainda incipiente internet um programa de computador (o Linux) e, junto com ele, o seu código (Leadbeater, 2009, p. 645), tem início o movimento mundial do software livre, que rapidamente ganha adeptos e provoca profundas transformações no mundo da computação, da economia, da cultura e, quiçá, da educação.

Como veremos mais adiante, para a educação, esses movimentos em torno de processos colaborativos são de fundamental importância já que possibilitam, potencialmente, a compreensão de que os aparatos tecnológicos contemporâneos, construídos e desenvolvidos historicamente, constituem-se elementos que contribuem com a construção de outras práticas sociais. 0 digital, de uma maneira em geral, e a internet, em especial, reconfiguram drasticamente, como afirma Mark Poster, as condições básicas do discurso e da recepção, já que, para ele, "a internet é mais um espaço social do que um objeto" (Poster, 2001, p. 176). Dessa forma, compreender a internet e, junto com ela, todas as demais tecnologias digitais que se articulam num processo de convergência tecnológica, significa pensá-las para além de meras ferramentas auxiliares do processos de produção de conhecimento e da educação (Pretto, 1996). Considerar a internet como espaço social, significa compreender que os seus efeitos

[...] são mais como os da Alemanha do que como os dos martelos. Os efeitos da Alemanha sobre as pessoas dentro dela é o de torná-los alemães (pelo menos na maior parte dos casos); os efeitos do martelo não é fazer com que as pessoas sejam martelos, embora os Heideggerianos e alguns outros possam discordar, mas pregar pontas metálicas na madeira. Enquanto entendermos a Internet como um martelo, vamos deixar de compreende-la como compreendemos o exemplo da Alemanha. O problema é que as perspectivas modernas tendem a reduzir a Internet a um martelo. Na grande narrativa da modernidade, a Internet é uma ferramenta eficaz de comunicação, que adianta os objetivos de seus usuários, entendidos como pré-constituídos de identidades instrumentais (Poster, 2001, p. 177, grifo nosso) ${ }^{5}$.

Nós, diferentemente da perspectiva "ferramenta eficaz de comunicação", pensamos na internet e em todas as tecnologias digitais, na 
sociedade, na escola e na educação em geral, como elementos que contribuem para uma radical transformação tanto da sociedade como da educação, sendo esse um dos grandes desafios de pesquisa no mundo contemporâneo. No entanto, essas transformações não estão correspondendo, na maioria das vezes, à forma como se elaboram as políticas públicas, nem como se estabelecem os processos educativos, trazendo para o cenário contemporâneo grandes confrontos. Aqui, pensar em políticas públicas para dar conta desses desafios é de fundamental importância, e o exemplo brasileiro, no campo da cultura, pode ser útil para uma melhor compreensão desse momento.

\section{Políticas públicas: avanço na cultura}

Algumas ações públicas estão em andamento no Brasil, através das políticas do governo federal no campo da cultura. Vislumbram-se novas possibilidades para a promoção de importantes articulações na linha aqui desenvolvida, com destaque para a aproximação entre a educação e a cultura. A implantação dos chamados Pontos de Cultura em diversos estados brasileiros, como parte do Programa Cultura Viva do Ministério da Cultura, tem sido uma das ações que tem possibilitado uma maior produção da chamada cultura digital. Esse projeto, criado pela Portaria $n^{\circ} 156$, de 06 de julho de 2004, é parte do Programa Nacional de Cultura, Educação e Cidadania - Cultura Viva, que tem como objetivo "[...] promover o acesso aos meios de fruição, produção e difusão cultural, assim como de potencializar energias sociais e culturais, visando a construção de novos valores de cooperação e solidariedade" (Brasil, 2004). A partir desse programa, o que se está a ver é a instalação de espaços para a produção de cultura digital, através do fornecimento de recursos, equipamentos e consultoria para que a juventude possa ter um local (físico) onde, com software livre, estão disponíveis equipamentos e ambientação para a produção multimídia, intensificando com isso a produção cultural local - cultura local essa que interage com o planetário através da internet. O uso do software livre, associado às discussões que vêm sendo travadas no âmbito federal sobre os direitos autorais, foi se constituindo a massa crítica para o fortalecimento dessa produção. Desde aquele momento, o Ministério da Cultura, principalmente através do seu então ministro Gilberto Gil, afirmava 
explicitamente sobre a importância desses movimentos. Em aula magna na Universidade de São Paulo, na época do lançamento do Programa, afirmava Gil:

Já temos no Brasil uma vasta experiência acumulada no campo do software livre e da inclusão digital, com centenas de projetos, protótipos e até mesmo uma reflexão acadêmica profunda, e esta ampla mobilização de pessoas, de inteligências, de criatividades, desemboca no próprio governo, que abraçou a causa e transformou a cultura digital em uma das suas políticas públicas (Gil, 2004).

As ações do governo Federal nesse campo, mais concentradas no âmbito da Cultura, buscaram fortalecer as manifestações da juventude de forma concreta. E, por isso, o próprio ministro afirmava ser essa uma questão "[...] de soberania coletiva, e portanto nacional" (Gil, 2004). Porém, os Pontos de Cultura pouco se articulam com o sistema educacional, conforme temos observado em função das nossas participações em reuniões, atividades e eventos mobilizadores do referido projeto. Esse nos parece ser um dos principais aspectos a serem considerados na busca de viabilizar uma maior aproximação das políticas públicas nesses campos, o que poderia contribuir para que a escola pudesse, efetivamente, vir a se constituir em pólo produtor de culturas e conhecimentos.

Associado a isso, as dificuldades de conexão, tanto dos pontos de cultura como das escolas, tem demandando também uma atenção redobrada em termos de políticas púbicas, não só da educação e da cultura, mas também no campo das telecomunicações, da ciência e da tecnologia. Não vamos aqui aprofundar o tema, mas vale destacar o importante movimento feito pelo governo federal no sentido de modificar a Lei Geral das Telecomunicações (LGT), de forma a garantir que até o ano de 2013, 55 mil escolas públicas estejam conectadas em banda larga à velocidade de $1 \mathrm{Mbps}$ (megabits por segundo) (Brasil, 2008).

Mas isso não é tudo. Necessário se faz, além disso, ampliar essas ações e políticas, incorporando também as discussões sobre o direito autoral, junto com as do software livre e das tecnologias livres, para, de fato, possibilitar a intensificação da capacidade de produção e uso dos produtos científicos e culturais produzidos pela humanidade (e pelas escolas). Esses movimentos, no entanto, sofrem cotidianamente, e no mundo todo, uma grande pressão por parte daqueles que detêm o poder econômico, com 
enormes interesses comerciais das indústrias do entretenimento, do software e hardware proprietários. Com relação ao acesso, uso e liberdade de ação na rede, é importante compreender as dificuldades que a sociedade enfrenta para que isso se configure plenamente. No $8^{\circ}$ Fórum Internacional do Software Livre ( $8^{\circ} \mathrm{FISL}$ ), realizado em Porto Alegre, em abril de 2007, foram várias as denúncias sobre a ação das empresas de telecomunicações que estão atuando com o objetivo de identificar os datagramas que passam pelas redes e com isso limitar o seu uso. As conversas telefônicas passam por softwares inteligentes que identificam conteúdo e, a partir disso, separam o que deve passar com melhor qualidade e o que não deve passar. Segundo os integrantes da mesa Neutralidade da internet: todos os datagramas são iguais perante a rede!, esses softwares, denominados de packet sniffers (espécie de farejadores de dados) já estão sendo implantados pelas operadoras em funcionamento no Brasil. Quem usa algum software para trocar arquivos na internet (peer-to-peer, $p-2-p)^{6}$ percebe logo uma queda de velocidade no download, como forma de desestimular o seu uso. $O$ que os especialistas apontam é que as operadoras vêm trabalhando no sentido de facilitar a navegação dentro de uma mesma rede e dificultar a interoperabilidade entre elas, oferecendo serviços privativos desses conglomerados, transformando o cidadão em usuário cativo e prisioneiro de um único fornecedor de conteúdos e serviços. Gustavo Gindre (2007) define mais claramente como funcionam esses farejadores, já que eles "[...] conseguem ler os cabeçalhos de milhões de datagramas ao mesmo tempo, e em tempo real, identificando origem, destino e tipo de conteúdo. Assim, um farejador pode descobrir se um usuário está, por exemplo, trocando arquivos peer-to-peer e, dependendo da decisão do dono da rede, degradar a qualidade do serviço" (Gindre, 2007, p. 151/2)." Encontramos o mesmo tipo de crítica ao acompanhar algumas falas nas listas de discussões sobre o tema. Em uma delas, um usuário reclama da qualidade do serviço quando está fazendo transferência de arquivos tipos $p-2-p$ e um outro esclarece que

alguns provedores de acesso aqui no Brasil e também em vários países, em vez de ampliarem seus links, preferem praticar o 'packet shapping' e até 'dropar' pacotes de softwares $p-2-p$. Eles possuem equipamentos e softwares de controle que conseguem ler os cabeçalhos dos pacotes transmitidos $e$ identificá-los como originários de programas $p-2-p$. Ato contínuo, dependendo do horário, tráfego ou numero de usuários online, reduzem a banda para este tipo de transmissão e podem até 'zerar' o 'ttl' (time to live) dos pacotes. Quando 
isso ocorre, é comum não reconhecerem esta prática. Nestes casos, obviamente, o povo das Centrais de Atendimento de Suporte (normalmente terceirizadas) ou não é informado, ou simplesmente não tem como admitir conhecimento do assunto 7 .

Essa não é, portanto, uma questão simples e exige uma ação mais articulada com todos os setores e esferas da sociedade civil, numa luta cujo lema poderia ser na rede, todos os bits são iguais, visando coibir esse tipo de prática. Uma ação política que não está restrita apenas aos membros das comunidades da ciência da informação e telecomunicações, mas uma mobilização de toda a sociedade e, nesse particular, é de grande importância o envolvimento dos educadores.

Políticas públicas pensadas e executadas de forma concorrente e isolada, seguramente não contribuem para os necessários avanços na questão. Aí reside, no nosso entendimento, o que qualificamos como diferencial da experiência que a Universidade Federal da Bahia (UFBA) está construindo e vivenciando no município de Irecê, a $500 \mathrm{~km}$ de Salvador/Bahia, onde a Faculdade de Educação mantém, em parceria com o poder público municipal, um programa de formação de professores no qual estão integrados as ações de inclusão sócio-digital, ponto de cultura Ciberparque Anísio Teixeira ${ }^{8}$, biblioteca pública, entre outros ${ }^{9}$. Essa experiência não será objeto de análise neste texto, mas vale ressaltar que o que se busca com esse projeto é estabelecer um diálogo intenso entre todas as áreas do conhecimento, articulando, na base, tanto as políticas públicas que nascem desarticuladas, como as diversas instâncias dos conhecimentos, dos saberes e das culturas. São essas, portanto, ações que contribuem com a ideia de pensar em educações, no plural, com bases bastante diferenciadas das atuais.

\section{Educações}

Começamos aqui a trazer o plural de forma mais intensa e, para tanto, necessário se faz pensar um pouco sobre a questão das linguagens, linguagens essas que estão intimamente ligadas e fortemente vinculadas aos aparatos tecnológicos disponíveis. Os jovens, apropriando-se das tecnologias, passam a usá-las de forma intensa, construindo novas formas de expressão e de linguagens. Particularmente em função da miniaturização das 
tecnologias, novas possibilidades de comunicação móvel são trazidas cotidianamente. O próprio ato de escrever modifica-se, a exemplo do intenso uso do dedo polegar para digitar as mensagens nos celulares. Os mais antigos ainda olham para o teclado de um celular com a ideia de "datilografar" ou digitar, usando os dedos indicadores. Matéria no International Herald Tribune destaca a importância que assume o dedo polegar na produção dessas novas escritas, não se restringindo apenas a esse tipo de comunicação móvel e instantânea, mas alcançando outros campos, com o desenho de produtos. A título de exemplo, a matéria (Rawsthorn, 2009) ${ }^{10}$ destaca o projeto do designer Ron Arad para que o vidro do perfume Kenzo possa ser aberto com o polegar no lugar do indicador, exatamente para contemplar essa geração que "escreve", e muito, com esse dedo. Outros elementos passam a fazer parte dessas novas linguagens, com a intensificação do uso de símbolos, ícones e imagens, não mais como meras ilustrações de textos escritos. São verdadeiras produções linguísticas, que acontecem com outros suportes que não apenas o papel e a caneta, assistidas por hardware e softwares especializados que auxiliam a produção dessas imagens. Com isso, também uma outra linguagem visual vem sendo produzida com o auxílio desses softwares que criam explicações visuais para fenômenos complexos como as teorias científicas e as transformações demográficas (Rawsthorn, 2009). Essa mudança na linguagem dos jovens não tem a ver só com o teclar, e sim com todo um universo mais amplo, que inclui os RPG, a música eletrônica, o hip-hop, as conversas nos chats (batepapos), nas comunidades de relacionamento como Orkut, Facebook, Myspace, Second Life, o intenso uso que se tem dado aos microblogues como o Twitter, Identi.ca, entre tantos outros. Essa juventude é, não resta a menor dúvida, uma juventude que produz mais, que escreve mais e se manifesta publicamente. Ao assim fazer, produz novos textos em diversos contextos que nos impõe repensar os próprios processos de alfabetização. Além disso, cresce de forma vertiginosa o uso das imagens em movimento. Os sítios de publicação de vídeo, sendo o Youtube o exemplo mais visível, mas não o único ${ }^{11}$, vêm mexendo radicalmente não só com o universo juvenil, mas, também, com o mundo adulto. Pesquisas indicam que cresce de forma vertiginosa a produção através dos sítios colaborativos, espaços onde todos passam a ser escritores e "jornalistas" e, por conta disso, esses blogues e microblogues com textos, sons e imagens, transformaram-se num enorme 
fenômeno contemporâneo. Pesquisa desenvolvida pelo Pew Internet \& American Life Project, divulgada em novembro de 2005, indicava que "[...] $57 \%$ dos adolescentes norte-americanos estavam criando conteúdo para a internet, de textos, fotos, áudios e vídeos". Importante lembrar que os primeiros blogues só apareceram em torno de 1997/1998, ou seja, esse é um fenômeno que tem pouco mais de 10 anos, sendo que, agora, acrescido de outras possibilidades que não somente os textos escritos, mas incorporando todo o universo multimídia.

Acrescente-se a isso o movimento em torno da troca de arquivos através dos sistemas ponto a ponto, que são redes distribuídas, nãohierárquicas e descentralizadas, nas quais cada usuário, ou seja, cada computador na rede, pode, ao mesmo tempo, exercer a função de cliente e servidor e, o mais importante, sem um gerenciamento central, fazendo com que a informação trafegue velozmente. Esse tipo de rede ganhou popularidade a partir dos programas de compartilhamento de música, inicialmente apenas associados ao formato mp3 (proprietário), mas que com o tempo passaram a ser usados para a circulação de músicas, filmes, vídeos e softwares.

Com tudo isso, a apropriação que a juventude vem fazendo desses aparatos tecnológicos tem lhe possibilitado ir além do mero consumo de informações: ela está produzindo intensamente culturas e conhecimentos. Num bem humorado texto, o escritor brasileiro Mário Prata adverte sobre esse fenômeno e, apesar da longa citação, penso que seja útil trazê-lo aqui:

Conheço quatro casos bem próximos. Gente que desmanchou o casamento de carne e osso por uma aventura no mundo das letras. Claro que estou me referindo aos encontros via Internet. Começa no chat, com o texto. Gostou do texto, leva para o reservado. E lá, rola. Eu mesmo já me envolvi perdidamente por dois textos belíssimos. Moças de vírgulas acentuadas, exclamações sensuais e risos de entortar qualquer coração letrado ou iletrado.

Sim, pela primeira vez nesta nossa humanidade já tão velhinha, as pessoas estão se conhecendo primeiramente pela palavra escrita. E lida, é claro.

[...] Quando eu ouvia um pai ou mãe dizendo "meu filho fica horas na Internet", todo preocupado, eu também ficava. Até que, por força do meu trabalho, comecei a navegar pela dita cuja.

E descobri, muito feliz da vida, que nunca uma geração de jovens brasileiros leu e escreveu tanto na vida. Se ele fica seis horas por dia ali, ou ele está lendo ou escrevendo. E mais: conhecendo pessoas. E amando essas pessoas. 
Jamais, em tempo algum, o brasileiro escreveu tanto. $E$ se comunicou tanto. $E$ leu tanto. E amou tanto.

[...] Quando comecei a escrever um livro pela Internet, muitos colegas jornalistas me entrevistavam (sempre a mim e ao João Ubaldo) perguntando qual era o futuro da literatura pela Internet. Naquela época eu não sabia responder a essa pergunta. Hoje eu sei e tenho certeza do que penso:

essa geração vai dar muitos e muitos escritores para o Brasil. E muita gente vai se apaixonar pelo texto e no texto.

Existe coisa melhor para um escritor do que concluir isso? (Prata, 2001, pp. 1416)

Mas nem todos pensam assim. Às vezes, de forma não tão sutil, essas diferenças de concepção sobre o uso das tecnologias vêm trazendo sérios confrontos para a escola, fazendo com que os educadores vivam um verdadeiro impasse, uma vez que, para boa parte dos jovens e adolescentes que já se relaciona com os videogames e com todos esses aparatos tecnológicos digitais, o relacionamento com as tecnologias se dá de forma transparente. Denominamos essa geração de geração alt+tab, em referência àquele conjunto de duas teclas que, se apertadas ao mesmo tempo, possibilitam a navegação e o processamento em janelas simultâneas nos computadores. Da mesma forma, Don Tapscott (1999) denomina essa turma de geração-net e Douglas Rushkoff (1999) a denomina de screenagers, sempre buscando reafirmar que essa é uma juventude que se relaciona de forma diferenciada com as tecnologias. Portanto, metaforicamente, podemos dizer que essa juventude já nasce "geneticamente modificada" para viver essa cultura. Claro precisa ficar, não custa repetir, que as políticas de acesso a todos esses recursos da informação e comunicação são fundamentais para que, efetivamente, toda a população possa ter acesso e conviver com o que denominamos de cibercultura.

É essa a juventude que chega à escola. Uma escola que vive uma crise por conta de diversas e históricas razões, uma das quais relacionadas com o crescimento da população e do número de alunos a serem atendidos. Uma escola que não dá conta de trabalhar com a diversidade de culturas dos que ali chegam ${ }^{12}$. Para tanto, as políticas públicas terminaram sendo, prioritariamente, baseadas em padronizações e na introdução de práticas centradas em uma lógica que mais se assemelha à linha de produção de uma indústria do que a processos de produção científica e cultural. $\mathrm{O}$ currículo 
continua sendo uma grade, mesmo quando é denominado com outras palavras. Mantém-se, assim, o currículo baseado numa lógica vertical, linear, centrada na ordem, contraditório com tudo que se faz contemporaneamente nas demais áreas do conhecimento, notadamente no campo da pesquisa e da produção do conhecimento. Dessa forma, passa o currículo a assumir o papel de regulador desses processos. Segundo Alfredo Veiga-Neto (2002, pp. 170171), "[...] pode[-se] dizer que o currículo é um artefato que foi engendrado tanto 'a serviço' da ordem e da representação quanto 'a serviço' das novas lógicas espaciais e temporais que se estabeleceram nos limiares da Modernidade".

Pensar em outras educações, neste momento contemporâneo, pode ser, por exemplo, pensar na ideia de uma escola 2.0, para fazer associação ao que foi denominado de web 2.0 - aquela do partilhamento on line intensivo -, pensando numa educação que compreenda as múltiplas possibilidades trazidas pela complexidade. Esse conjunto de relações leva-nos a pensar nos caminhos e no caminhar. A pensar no labirinto, enquanto uma importante metáfora para os processos educacionais. Pensar, quem sabe, na ideia de uma escola-labirinto, espaço com magníficas possibilidades de caminhos diferenciados, onde o se perder é valorizado, porque possibilita uma enorme diversidade de caminhos e soluções; onde chegar a um lugar é importante, claro, mas sem que isso imponha a perda da riqueza do caminhar, do se perder e do experimentar as inúmeras possibilidades trazidas pelo próprio caminhar (e agora, navegar). Espaço, portanto, da criação e da experimentação. Em oposição a isso, contudo, ainda encontramos uma escola centrada na objetividade, com rígidos procedimentos burocráticos para dar conta de si própria enquanto parte de um enorme sistema e, ainda, fechada em si mesma, na crença de que, com controles mais rígidos, se pode chegar a melhores resultados, o que, de fato, não está acontecendo, como os números indicam. Pesquisa realizada pelo Instituto Montenegro ${ }^{13}$, em parceria com a ONG Ação Educativa, apontou a situação da alfabetização no Brasil. Para tal, foi elaborada uma classificação do analfabetismo a partir de quatro níveis, a saber: analfabetismo, alfabetismo rudimentar, alfabetismo básico e alfabetismo pleno. Os resultados foram assombrosos, uma vez que, no ensino médio, entre os jovens de 15 a 24 anos, apenas $41 \%$ tem domínio pleno dos números e $57 \%$ domínio pleno das letras, resultado absolutamente 
lamentável, considerando que essa pode ser parte da população que não terá acesso a mais do que esse nível de escolaridade. Os dados claramente indicam o enorme deficit nas políticas educacionais e, mais uma vez, este estado de coisas só será superado se retomarmos a ideia de rede, articulando todo o sistema, da pré-escola à pós-graduação, e esse com os demais sistemas: da cultura, da ciência e tecnologias, entre tantos outros.

'Rede' impõe pensar na multiplicidade de pontos, valores, culturas. No entanto, essa diversidade não pode ser compreendida apenas como um elemento "folclórico" ou animador dos processos educacionais, aceita na educação apenas no início dos processos, na entrada, como em uma máquina que depois vai diluindo as diferenças, transformando, ou melhor, formatando - palavra aqui usada propositalmente - o diferente no igual, na mesmice. Em outras palavras, a educação, assim continuando, constitui-se num sistema centrado na transformação do outro no Eu. Alfredo Veiga-Neto, em dois importantes textos sobre as questões curriculares e a relação cultura e educação, denomina esse processo, no âmbito da cultura, de "máxima isotropia", ou seja,

uma situação sociocultural em que, no limite, cada ponto do espaço social guarda uma relação de identidade com os pontos adjacentes, de maneira que, se atingido tal limite, o conjunto apresentar-se-ia inteiramente homogêneo e com um risco social igual azero. Em outras palavras, isso significa o rebatimento de tudo e de todos a um Mesmo; em termos culturais, significa uma identidade única e a rejeição de toda e qualquer diferença (Veiga-Neto, 2003, p. 10).

Felizmente, são inúmeras as possibilidades de transformação dessa realidade e muitas delas estão sendo implantadas e conduzidas por professores e professoras atuantes e animados, lutando contra a precariedade das condições profissionais e de infra-estrutura das escolas. No campo das tecnologias da informação e comunicação, torna-se necessário intensificar a apropriação das TICs enquanto elementos de cultura, e não apenas como aparatos tecnológicos (muitas vezes presentes nas escolas por pressão da indústria!) que ilustram ou facilitam os processos escolares. Ou seja, temos que afastar definitivamente a perspectiva instrumental da introdução das TICs na escola, o tal martelo referido anteriormente por Mark Poster. Esses equipamentos, e todos os sistemas a eles associados, são constituidores de culturas e, exatamente por isso, demandam olharmos a 
educação numa perspectiva plural, afastando a ideia de que educação, cultura, ciência e tecnologia possam ser pensadas enquanto mecanismos de mera transmissão de informações, o que implica pensar em processos que articulem todas essas áreas concomitantemente.

No campo das tecnologias, uma ação que se tem mostrado de grande importância é a aproximação com o movimento do software livre e das possibilidades trazidas pelas tecnologias livres, ao resgatar, para o ambiente da escola, a perspectiva de colaboração. Associado a isso, os movimentos de democratização das produções, através das chamadas licenças criativas (copyflet e creative commons), intensificam uma ideia que nos é muito cara: a ênfase na intensa criação. Esses são movimentos que buscam fazer circular as informações, produzir e reproduzir permanentemente, remixando tudo, recriando em cima do já criado. Acredito que, a partir desses elementos, podemos também pensar nos processos denominados de 'inclusão digital' com um outro olhar, afastando-se, assim, da perspectiva limitada do chamado treinamento para o mercado de trabalho. Temos defendido uma outra perspectiva de inclusão que supere a dramática dicotomia: para o filho do rico, todas as condições são oferecidas, com um quarto tecnológico, com computadores de alto processamento, conectados em banda larga, suporte gratuito e, o mais importante, a liberdade quase total para se fazer o que desejar; para o filho do pobre, acesso através das escolas, telecentros e infocentros, com aulas de informática para o ensino de planilhas, processadores de texto ou coisas do tipo, geralmente de forma muito entediante e com softwares proprietários. Investe-se muito e pouco se modifica essa realidade, uma vez que este tipo de política de "inclusão" termina sendo impregnada por uma "pedagogização" exagerada dos processos, fazendo com que a distância entre aqueles que têm acesso e os que não têm aumente cada vez mais, reforçando a estratificação já existente em nossa sociedade.

Como já referido anteriormente em relação à alfabetização, também não é possível pensá-la de forma isolada, no singular, e, muito menos, apenas na ideia de uma alfabetização digital. Penso que é imperativo, aqui também, considerar as alfabetizações, com a perspectiva plural de novo presente, fortalecendo-se, com isso, todo o sistema educacional, formal e não-formal. 0 que propugnamos é que professores e alunos deixem de ser meros atores do 
processo educacional e passem a ser considerados - cada um individualmente e enquanto grupo - autores do processo. Para tal, no campo das TICs, um dos aspectos a considerar é a necessidade de se superar a ideia de montagem de portais de serviços que distribuam informações, produzidas de forma centralizada por especialistas, para consumidores localizados nas escolas. Penso ser importante a constituição de comunidades virtuais de aprendizagem, articulando toda a rede, em ações peer-to-peer, com escolas, professores, alunos e comunidade, atuando de forma intensa e permanente na incorporação de todas as manifestações de cada uma das regiões, do país e do mundo, promovendo o diálogo destas manifestações com as oriundas de outras regiões, da alta cultura e da ciência, mas sempre em processos horizontalizados.

Essas reflexões estão baseadas nas primeiras ideias trazidas por Luis Felippe P. Serpa ao considerar as pedagogias da diferença em oposição às tradicionais pedagogias da assimilação. Pedagogias que tenham o diferente como fundante, não colocando como referência a identidade, mas o próprio diferente (Pretto \& Serpa, 2001). Busca-se com isso o enaltecimento da diferença, sendo ela "produtora de alteridades", como nos propôs em conversa pessoal Wladimir Garcia, da Faculdade de Educação da Universidade Federal de Santa Catarina. Assim, as expressões que passam a fazer parte do vocabulário dos educadores, são fluxo, rede e movimento, em lugar das já conhecidas linearidade, currículo fechado ou distribuído, treinamento, entre tantas outras.

Mas as ações de produção colaborativa podem ir mais além, incorporando a ideia de uma produção peer-to-peer para os materiais educacionais, consubstanciando um ciclo virtuoso de produção, remixagem e uso que podem trazer novos elementos fundantes dos processos educacionais, como também propõe Yochai Benkler (2005). Essa produção, descentralizada e fortalecida pela atuação autoral de professores e estudantes nas escolas, dialogaria de forma intensa com os conhecimentos e as culturas instituídas. Efetivada essa produção - desafio não pequeno, sabemos -, com a possibilidade de uso e remixagem amplos por todos, ainda teremos importantes desafios. Como afirma Benkler, a partir daí a questão crucial passa a ser saber "se temos suficientemente bons motores de busca e plataformas de integração que possam permitir a alunos e 
professores pesquisar, utilizar e darem o necessário retorno para o aperfeiçoamento desses recursos educativos distribuídos". Para ele, "[...] não há uma clara necessidade de imposição de uma ordem coerente mas apenas um mecanismo de pesquisa, compartilhamento e transformação [remixagem]. A trajetória do crescimento é mais semelhante ao de sites na Web do que dos livros didáticos" (Benkler, 2005, p. 25, tradução do autor). Assim, professores e jovens passam a fazer parte da produção dos próprios recursos disponíveis para a sua educação e a dos demais, e não simplesmente consumindo produtos prontos, trazidos de fora. Isso sem afastar a produção histórica da humanidade, mas sim com ela estabelecendo um diálogo franco e aberto, favorecido pelas redes, articulando de forma intensa o saber local com o saber planetário, remixando conhecimentos e culturas, no tempo e no espaço.

A montagem de um sistema fortalecido como esse significa pensar nas redes colaborativas, centradas na generosidade, na cooperação, e isso nos traz um outro problema: a estrutura física das escolas. Fica muito difícil continuar a pensar na rede escolar com uma arquitetura que não favoreça essas novas e necessárias posturas de professores, alunos e de todo o pessoal da gestão da escola. Esse é um campo emergente de pesquisa, e um grupo de professores das Faculdades de Educação e Arquitetura da UFBA tentou dar início a um projeto intitulado "Construindo uma nova escola: mapeamento da produção no campo da arquitetura e educação"14, tendo resultado, lamentavelmente, apenas na produção de uma tese de doutorado e uma dissertação de mestrado. O que se propunha era identificar as experiências existentes de ação conjunta de educadores e arquitetos, com o objetivo de promover uma "[...] análise do processo de concepção e criação dos espaços educacionais, através de um estudo que [identificasse] as produções acadêmicas e técnicas dos projetos arquitetônicos e pedagógicos e suas materializações" e, com isso, contribuir para que se pense em outros espaços - reais e virtuais - para a educação. Obviamente, aqui a inspiração era Anísio Teixeira e a sua Escola Parque, no bairro da Caixa D'Água, em Salvador, Bahia15. Transformações essas que, não sendo simples, demandam um outro olhar para a educação, um olhar em profunda sintonia com o escritor moçambicano Mia Couto, uma vez que acreditamos que a busca pelo conhecimento não se dá na perspectiva "de sermos donos" de qualquer coisa: o que buscamos é ser "[...] mais companheiros das criaturas 
vivas e não vivas com quem partilhamos esse universo" (Couto, 2005). Entre essas criaturas estão os professores, que precisam ser fortalecidos. Investir fortemente na formação de professores, nas condições de trabalho e salário são condições básicas para as mudanças que se impõem a todo o sistema educacional. $O$ professor tem que ser valorizado enquanto elemento que possa articular essas diversas instâncias na produção do conhecimento e das diferenças trazidas pelos seus alunos. Assim, e somente assim, com o professor retomando o seu papel de liderança científica, cultural, ética, a escola pode assumir a condição de se constituir num efetivo espaço coletivo de culturas e conhecimentos, oferecendo aos filhos dos pobres aquilo que os filhos dos ricos têm em casa, como já dito pelo educador baiano Anísio Teixeira, na década de 50 do século passado. Este é, seguramente, um dos desafios fenomenais que temos pela frente, e, aqui, todo o cuidado é pouco, pois os resultados não são imediatos. Mas esses podem ser importantes passos para a construção de um planeta solidário e sustentável.

\section{Notas}

1 Texto concluído durante o pós-doutoramento do autor na Universidade Trent de Nonttingham (bolsa CAPES), como resultado parcial da pesquisa 'Políticas Públicas Brasileiras em Educação e Tecnologia da Informação e Comunicação: superando as tecnologias educacionais' (apoio CNPq).

2 http://www.ekac.org/.

3 Entre outros, ver o livro Mídias digitais: convergência tecnológica e inclusão social, organizado por Barbosa Filho, Castro, e Takashi (2005), e a pesquisa de doutorado de Simone de Lucena Ferreira (2008).

4 http://setiathome.ssl.berkeley.edu/.

5 Mantivemos na citação a escrita de internet com o "i” maiúsculo, o que não fazemos mais, assim como não escrevemos com maiúsculo outras tecnologias como telefone, computador, jornal.

6 Peer-to-peer (p-2-p): troca de arquivos de forma colaborativa e compartilhada, como no caso de música e vídeos através de diversos programas como e-mule, bittorrent, entre outros.

7 http://www.forumboadica.com.br/viewtopic.php?t=111584\&highlight=\&sid= 67e21f8577b8580b08d924001d60d040, capturado em 01/05/2007.

8 http://www.ciberparque.faced.ufba.br/.

9 http://www.faced.ufba.br/irece. 
10 Grato a Silvio Meira, em sua coluna Dia a Dia, Bit a Bit, no Terra Magazine, pela indicação desse aspecto da questão.

11 //www.youtube.com, mas ver também //fora.tv, //vodpod.com, //video.yahoo.com, I/video.google.com, entre outros.

12 O filme "Entre os Muros da Escola" (Entre les murs, França, direção de Laurent Cantet, do romance de mesmo nome escrito por François Bégaudeau), Palma de Ouro no Festival de Cannes de 2008, retrata de forma muito clara essa diversidade e, mais do que tudo, destaca o importante papel do professor, que passa a ser de forma intensa um "permanente negociador das diferenças" (Pretto, 2001).

13 http://www.ipm.org.br, capturado em 20/04/2007.

$14 \mathrm{http}: / / w w w . g e c . f a c e d . u f b a . b r / t w i k i / b i n / v i e w / G E C / A r q u i E d u c a$.

15 No momento de elaboração final desse texto, durante o pós-doutoramento do autor, constatamos a existência, na Inglaterra, de uma política pública em torno das edificações escolares britânicas denominada "Construindo escolas para o futuro". Mais informações consultar http://www.partnershipsforschools.org.uk.

\section{Referências}

Barbosa Filho, A., Castro, C., \& Takashi, T. (2005) (Org.). Mídias digitais: convergência tecnológica e inclusão social. São Paulo: Edições Paulinas.

Benkler, Y. (2005). Common Wisdom: peer production of educactional materials. Center for Open and Sustainable Learning (COSL), Universidade de Utah, EUA. Disponível em http://csol.usu.edu

Benkler, Y. (2006). The wealth of networks: how social production transforms markets and freedom. London: Yale University Press.

Brasil (2008). Decreto $\mathrm{n}^{\circ}$ 6.424, de 4 de Abril de 2008. Disponível em $\mathrm{http} / / \mathrm{www}$.senado.gov.br

Brasil . Ministério da Cultura (2004). Portaria 156 de 06 de julho de 2004. Disponível em http://www.cultura.gov.br/documentos/ConcursoseEditais_MinC/2004/SDPC/ portaria/pcv_portaria1.doc

Castells, M. (1996). The Rise of the Network Society. New York: Blackwell.

Cini, M. (1998). Um paradiso perduto: dall'universo delle leggi naturali al mondo dei processi evolutivi. Milão: Feltrinelli.

Couto, M. (2005). Pensatempo. Lisboa: Editora Caminho.

Dias, L. C. (1995). Redes: emergência e organização. In I. E. Castro, P. Gomes \& R. Corrêa (Org.), Geografia: conceitos e temas (pp. 141-162). Rio de Janeiro: Bertrand Brasil.

Ferreira, S. L. (2008). Possibilidade para a Educação em Rede com a TV Digital no Brasil. Tese de Doutorado. Salvador: Faculdade de Educação, Universidade Federal da Bahia. 
Feyerabend, P. K. (1996). Matando o Tempo: uma autobiografia. São Paulo: Ed. UNESP.

Gil, G. (2004). Cultura digital e desenvolvimento. Aula Magna na Universidade de São Paulo. Disponível em http://www.cultura.gov.br/site/2004/08/10/ ministro-dacultura-gilberto-gil-em-aula-magna-na- universidade-de-sao-paulo-usp

Gilder, G. (1994). Life after Televison. New York: W.W. Norton \& Company.

Gindre, G. (2007). Agenda de regulação: uma proposta para o debate. In S. S. Amadeu, Comunicação Digital e a construção do Commons: Redes virais, Espectro Aberto e as Novas Possibilidades de regulação (pp. 129-174). São Paulo: Fundação Perseu Abramo.

Himanen, P., Torvalds, L., \& Castells, M. (2002). The hacker ethic. London: Random House Trade.

Leadbeater, C. (2009). We Think: the Power of Mass Creativity. London: Profile Books.

Piscitelli, A. (2002). Ciberculturas 2.0: en la Era de las Máquinas Inteligentes. Buenos Aires: Paidós.

Poster, M. (2001). What's the Matter with the Internet. Minneapolis: University of Minnesota Press.

Prata, M. (2001). Minhas tudo: incluindo sexo, drogas e rock and roll. E umas mulheres peladas. Rio de Janeiro: Objetiva.

Pretto, N. (1996). Uma Escola sem/com Futuro: Educação e Multimídia. Campinas, Papirus.

Pretto, N. (2006). Mídia, currículo e o negócio da educação. In A. F. Moreira (Org.), Currículo, Cotidiano e Tecnologias (pp. 111-148). Araraquara, SP: JM Ed.

Pretto, N., \& Serpa, L. F. P. (2001). A educação e a sociedade da informação. In P. Dias (Org), Challenges 2001. Actas da II Conferência Internacional de Tecnologias da Informação e Comunicação na Educação. Braga: Centro de Competência Nónio Século XXI da Universidade do Minho.

Rawsthorn, A. (2009). What technology has taught us at dizzying speed. International Herald Tribune, Nova Iorque, 25 Janeiro. Disponível em http://www.iht.com/ articles/2009/01/23/ arts/design26.1-412695.php?page =1

Rushkoff, D. (1999). Um Jogo chamado Futuro: como a Cultura dos Garotos pode nos Ensinar a Sobreviver na Era do Caos. Rio de Janeiro: Revam.

Takahashi, T. (2000). Sociedade da Informação no Brasil: Livro Verde. Brasília: Ministério da Ciência e Tecnologia.

Tapscott, D. (1999). Geração Digital: a Crescente e Irreversível Ascensão da Geração Net. São Paulo: Makron Books.

Veiga-Neto, A. (2003). Cultura, culturas e educação. Revista Brasileira de Educação. 23, 5-15. Disponível em http://www.scielo.br

Veiga-Neto, A. (2002). De geometrias, currículo e diferenças. Educação e Sociedade, 23 (79), 163-186. Disponível em http://www.scielo.br

Wrey, R. (2008). Cash in hand: why Africans are banking on the mobile phone. The Guardian, Londres, 17 June. Disponível em http://www.guardian.co.uk/ business/ 2008/jun/17/telecoms.telecoms 


\title{
EDUCATION CHALLENGES IN THE DIGITAL ERA: EDUCATIONS
}

\begin{abstract}
The paper initially presents an overview of scientific and technological development, the global mainstream media system and the coexistence of some languages, which are intensively articulated from and by the great presence of digital technologies. An analysis is made of the set up process of digital networks and collaborative processes and Brazilian public policies for the digital culture, in particular the use of collaborative networks emphasising open/free software and collective production. From this the paper discusses the importance of the relationship between education and culture. We develop the idea of the intense use of horizontal and collaborative networks in educational processes which empower teachers and students to produce culture and knowledge. Finally, we reflect more closely on thinking of education from a plural perspective, i.e. educations.
\end{abstract}

Keywords

Education; Digital Culture; Digital communication; Networks

\section{EL RETO DE EDUCAR EN LA ERA DIGITAL: EDUCACIONES}

\section{Resumen}

El artículo presenta una visión general del desarrollo científico y tecnológico de la comunicación en diferentes lenguajes (co)existentes que están vinculados intensamente debido a la enorme presencia de las tecnologías digitales. Analiza el despliegue de redes digitales, procesos colaboradores de producción de conocimiento y de las políticas públicas brasileñas para el campo de la cultura digital, haciendo hincapié en el uso de redes de intercambio, con énfasis en el software libre y la producción colectiva. A partir de estas premisas, se discute la importancia de la relación entre educación y 
118 Nelson de Luca Pretto

cultura. Se desarrolla la idea del uso intensivo de las redes de colaboración en los procesos educativos, con la creación de comunidades horizontales de producción de culturas y conocimientos. Al final, se hace una reflexión más detallada sobre la propuesta de pensar en la educación desde una perspectiva plural, es decir, en educaciones.

Palabras clave

Educación; Cultura Digital; Comunicación digital; Networks

Recebido em Outubro/2009 Aceite para publicação em Agosto/2010

Toda a correspondência relativa a este artigo deve ser enviada para: Nelson de Luca Pretto, $A v$. Cons. Pedro Luis, 217/304 - 41950-610, Salvador, Bahia, Brasil. Telef.: +55 71 32837205/87791906; e-mail: nelson@pretto.info, URL: www.pretto.info. 